\title{
High Smac/DIABLO expression is associated with early local recurrence of cervical cancer
}

\author{
Abril Arellano-Llamas ${ }^{1}$, Francisco J Garcia ${ }^{2}$, Delia Perez ${ }^{3}$, David Cantu 4 , \\ Magali Espinosa ${ }^{1}$, Jaime G De la Garza ${ }^{1}$, Vilma Maldonado*1 and \\ Jorge Melendez-Zajgla*1
}

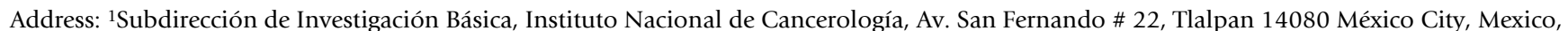
2Departamento de Anatomia Patologica, Instituto Nacional de Pediatria, Insurgentes Sur \# 3700, Coyoacan 04530 México City, Mexico,

${ }^{3}$ Subdireccion de Patologia, Instituto Nacional de Cancerología, Av. San Fernando \# 22. Tlalpan 14080 México City. Mexico and ${ }^{4}$ Subdirección de Cirugía, Instituto Nacional de Cancerología Av. San Fernando \# 22. Tlalpan 14080 México City. Mexico

Email: Abril Arellano-Llamas - abrilarellano@gmail.com; Francisco J Garcia - momoxco@yahoo.com;

Delia Perez - madeliapmg@yahoo.com.mx; David Cantu - dcantu3@excite.com; Magali Espinosa - magali.espinosa@gmail.com; Jaime G De la Garza - jgdelagarza@starnet.net.mx; Vilma Maldonado* - vilmaml@gmail.com; Jorge Melendez-Zajgla* - jorgezajgla@ssa.gob.mx

* Corresponding authors
\end{abstract}

Published: 26 October 2006

BMC Cancer 2006, 6:256 doi:10.1 186/147|-2407-6-256
Received: 22 August 2006

Accepted: 26 October 2006

This article is available from: http://www.biomedcentral.com/147I-2407/6/256

(C) 2006 Arellano-Llamas et al; licensee BioMed Central Ltd.

This is an Open Access article distributed under the terms of the Creative Commons Attribution License (http://creativecommons.org/licenses/by/2.0), which permits unrestricted use, distribution, and reproduction in any medium, provided the original work is properly cited.

\section{Abstract}

Background: In a recent pilot report, we showed that Smac/DIABLO mRNA is expressed de novo in a subset of cervical cancer patients. We have now expanded this study and analyzed Smac/ DIABLO expression in the primary lesions in 109 cervical cancer patients.

Methods: We used immunohistochemistry of formalin-fixed, paraffin-embedded tissue sections to analyze Smac/DIABLO expression in the 109 primary lesions. Seventy-eight samples corresponded to epidermoid cervical cancer and $3 \mathrm{I}$ to cervical adenocarcinoma. The median follow up was 46.86 months (range 10-186).

Results: Smac/DIABLO was expressed in more adenocarcinoma samples than squamous tumours $(71 \%$ vs $50 \% ; p=0.037)$. Among the pathological variables, a positive correlation was found between Smac/DIABLO immunoreactivity and microvascular density, a marker for angiogenesis ( $\mathrm{P}$ $=0.04)$. Most importantly, Smac/DIABLO immunoreactivity was associated with a higher rate of local recurrence in squamous cell carcinoma $(p=0.002$, log rank test). No association was found between Smac/DIABLO and survival rates.

Conclusion: Smac/DIABLO expression is a potential marker for local recurrence in cervical squamous cell carcinoma patients.

\section{Background}

Apoptosis is a type of programmed cell death morphologically characterized by membrane blebbing, nuclear and cytoplasmic condensation and the formation of vesicles containing intact organelles [1]. Deregulation of this proc- ess has been implicated in numerous pathological conditions including cancer. Two well-characterized apoptotic pathways converge in caspase activation: the death receptor pathway and the intrinsic or mitochondrial pathway [2]. The intrinsic pathway is triggered by various extracel- 
lular and intracellular stresses such as growth-factor withdrawal, hypoxia, DNA damage and oncogene induction. These signals converge on the mitochondria, resulting in the regulated release of cytochrome $\mathrm{c}$ and other proapoptotic molecules. This leads to assembly of the apoptosome, a complex containing cytochrome $c$, apoptotic protease activating factor 1 and caspase 9. This protein complex in turn initiates the activation of effector caspases [3]. To avoid unregulated activation of these enzymes, members of the Inhibitors of Apoptosis Proteins (IAPs) family bind caspases and prevent their activation, thus tightly controlling the induction of apoptosis [4]. In cells undergoing apoptosis, IAPs are inactivated by interacting with proteins containing the so-called IBM (IAP-binding motif) $[4,5]$. One of these IBM proteins is the recently identified Smac/DIABLO. Smac is a proapoptotic protein that in healthy cells resides in the intermembrane space in the mitochondria $[6,7]$ but is released into the cytosol during apoptosis, where it interacts with IAPs and disrupts their ability to bind caspases [8]. Smac interacts with all mammalian IAPs examined so far: XIAP, CIAP-1, cIAP-2, survivin and ML-IAP $[6,7,9,10]$. In addition to its ability to disrupt caspase inhibition by IAPs, Smac delivers cIAP1 and CIAP2 for rapid degradation by autoubiquitination [11]. The balance of Smac/DIABLO and IAPs determines the threshold for a variety of apoptotic stimuli.

IAPs are commonly over-expressed in human cancers [1214], contributing to the carcinogenic process and to the resistance of these cells to chemotherapy [15]. However, the importance of Smac/DIABLO, a partner in the caspase inhibitory system, has been less well explored. Patients with lower Smac/DIABLO levels in lung [16] and renal [17] tumors have been shown to have worse prognoses. This indicates that Smac expression may play a role in the progression of several neoplastic diseases and could be useful for prognosis. In a recent pilot report using RT-PCR, we showed that Smac/DIABLO is expressed de novo in a subset of cervical cancer patients [18]. The study only analyzed 41 cancer samples, precluding a more detailed analysis. In the present work we have analyzed Smac/DIABLO expression in formalin-fixed, paraffin-embedded tissue sections from primary lesions in 109 cervical cancer patients.

\section{Methods}

\section{Tumor samples}

One hundred and nine cervical cancer samples were obtained from consecutive patients recruited in the Gynecological Cancer Clinic at the Instituto Nacional de Cancerologia of Mexico between January 1990 and December 1993. Seventy-eight corresponded to epidermoid cervical cancer and 31 to cervical adenocarcinoma. Written consent was obtained from the patients before the samples were collected. Tumors were staged according to the Inter- national Gynecology and Obstetric Federation (FIGO) system. The samples comprised 6 in stage IB, 2 in IIA, 62 in IIB, 15 in IIIA and 24 in IIIB.

\section{Histology}

Histopathology was graded according to the WHO (World Health Organization) classification system.

\section{Immunohistochemistry}

To perform immunohistochemistry, $4 \mu \mathrm{m}$ thick sections were obtained from archival blocks, deparaffinized and rehydrated in graded ethanol. Antigen retrieval was done by heating the slides ( $5 \mathrm{~min}$ in a microwave oven) in citrate buffer at $\mathrm{pH}$ 6.0. Endogenous peroxidase activity was blocked with $3 \% \mathrm{H}_{2} \mathrm{O}_{2}$ for $5 \mathrm{~min}$. Sections were incubated with primary antibody at 1:75 dilution (Anti-Smac/DIABLO, Calbiochem Cat: PC574) for $30 \mathrm{~min}$ at room temperature, rinsed with PBS, and reincubated with a secondary antibody (Rabbit Polydetector Bio SB. Cat BSB0221) for $30 \mathrm{~min}$. The peroxidase substrate was diaminobenzidine (DAKO, Denmark). Slides were finally counterstained with Gill's hematoxilin for $8 \mathrm{~min}$. As expected from our previous results [18], Smac/DIABLO staining was undetectable in normal cervix (not shown). To further validate the staining, three aleatory biopsies of gastric carcinoma were used as positive controls, based in a previous report showing that $70 \%$ of these tumors presented positive staining [19]. All three biopsies showed a strong positive cytoplasmic signal. Negative controls were included to verify specificity. The antibody used reacts specifically with Smac/DIABLO, as verified by western blot assays of cervical cancer cells with depleted (using an antisense approach) or overexpressed Smac (Ceballos, G., submitted)

\section{Microvessel Density (MVD)}

Microvessel density was determined as described in [20]. Briefly, immunostaining for CD34 was performed in using a monoclonal antibody (anti CD34 monoclonal Class II, clone QBEnd/10, DAKO, Denmark) with a commercial kit, as directed by the manufacturer (LSAB peroxidase, DAKO, Denmark). Areas of cancer tissue with distinct microvessels ("hot spots") were selected and microvessel density was determined by counting all vessels at a total magnification of 200×. All slides were evaluated blindly and independently by two pathologists. Routine haematoxylin and eosin was used to evaluate grade and lymphovascular involvement.

\section{Evaluation of Smac/DIABLO expression}

Smac/DIABLO immunoreactivity was evaluated by two observers in a blind procedure. The slides were assessed for intensity (0: negative, 1: less intense than positive control, 2: equal intensity to control, 3 : more intense than control) and positive area (percentage). 

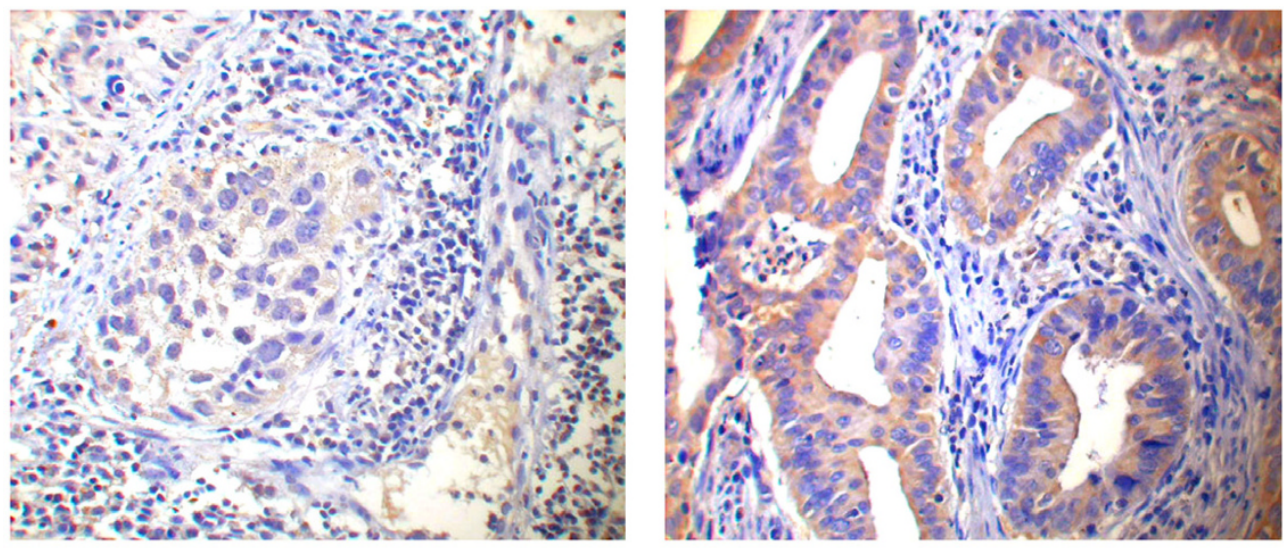

\section{Figure I}

Photomicrographs showing Smac/DIABLO immunoreactivity in representative cervical cancer samples. Staining was predominantly cytoplasmic and involved only tumor cells. Left panel: low intensity (I) score. Right panel: high intensity (2) score. Total magnification: 400x. Procedures were performed as described in "Materials and Methods".

\section{Statistical analysis}

To investigate correlations between clinical variables and Smac/DIABLO positive immunostaining we used Chi square tests (stage, histology and grade) and Mann-Whitney tests (age, lymphovascular permeation and microvascular density). Survival and recurrence were evaluated using Kaplan-Meier curves for each variable and the curves were compared by a log rank test. The statistical package SPSS 12.0 was used for analyses and statistical significance was accepted when the $p$ value was less than 0.05 .

\section{Results}

The present study included 109 patients with a mean age of 47.14 years (range 25-73), similar to reports elsewhere [20]. Thirty-one of them corresponded to adenocarcinoma and 78 to squamous cell carcinoma. The median age at diagnosis was 47 years, and the median follow up was 46.86 months (range 10-186). The patients were mostly in advanced stages, distributed as follows: 6 cases corresponded to stage I, 64 to stage II and 39 to stage III. Histologically, $11 \%$ of the samples were well differentiated, 33\% moderately well differentiated and 56\% poorly differentiated.

Sixty-one (56\%) of the patients presented positive immunostaining for Smac/DIABLO, a slightly higher percentage that in our previous report (31.7\%) [18]. Staining was predominantly cytoplasmic and involved only tumor cells; stromal cells were negative (Fig. 1). A similar number of samples from different stages or histopathological grades were positive for Smac/DIABLO (Table 1). Interestingly, a larger number of adenocarcinoma samples were Smac immunopositive (71\% vs 50\%; $\mathrm{p}=0.037$ ) (Table 1 ). Among the pathological variables, we found that positive
Smac/DIABLO samples presented a higher microvascular density, a factor previously shown to have prognostic significance in cervical cancer $(\mathrm{p}=0.04)$ [20] (Table 2). No other correlation was found (not shown).

To assess whether the level of Smac/DIABLO expression correlated with the clinical variables analyzed, we produced semi quantitative scores of the immunoreactive area and intensity (see Material and Methods). When these scores were analyzed, we found no differences in

Table I: Smac/DIABLO positive immunoreactivity in cervical cancer samples.

\begin{tabular}{ccc}
\hline Variable & No. patients $(\mathrm{n}=109)^{*}$ & $\mathbf{p}$ \\
\hline FIGO stage & $5(83)$ & \\
II & $35(54)$ & 0.403 \\
III & $21(53)$ & \\
Histology of tumors & & \\
Squamous cell & $39(50)$ & 0.037 \\
Adenocarcinoma & $22(71)$ & \\
Grade & & 0.19 \\
Well differentiated & $9(75)$ & \\
Moderately differentiated & $22(61)$ & \\
Poorly differentiated & $30(49)$ & \\
Current status & & \\
Alive & $32(59)$ & \\
Dead & $29(53)$ &
\end{tabular}

*Number of patients expressing Smac/DIABLO and percentage of positive patients in the group (in parenthesis). Chi square was used to test for differences. No significant differences were found when analyses were performed in data dichotomized for histology. 
Table 2: Smac/DIABLO positive immunoreactivity in squamous cervical cancer samples.

\begin{tabular}{cccc}
\hline Smac/DIABLO & Median & $\boldsymbol{A D}$ & $\boldsymbol{P}$ \\
\hline & Age & & \\
Negative & 46.58 & 9.17 & 0.621 \\
Positive & 47.52 & 10.6 & \\
& & & \\
Legative & 0.51 & 0.72 & 0.479 \\
Positive & 0.39 & 0.63 & \\
& & & \\
& MVD & & \\
Negative & 18.02 & 9.7 & 0.047 \\
Positive & 22.93 & 8.93 &
\end{tabular}

Age, Lymphovascular Permeation (LVP) and Microvascular Density (MVD) values for positive and negative Smac/DIABLO patients. AD: Absolute Deviation. Mann-Whitney test was used to verify significant differences. Similar differences were found when analyses were performed in adenocarcinoma samples.

clinical stage, histology or grade in neither squamous nor adenocarcinoma samples (Table 3 and 4). Similarly, patients with different disease status presented similar scores (Fig. 2). When a more detailed analysis was performed, we found that squamous cell carcinoma patients with local recurrence had higher Smac/DIABLO immunoreactivity than non-recurrent or patients with distant recurrences ( $\mathrm{p}=0.003$ ) (Fig. 3) No correlation was found for adenocarcinoma samples. To determine whether a higher Smac/DIABLO score could predict local recurrence, we divided the patients into two groups: low (less than 40 percent) or high (more than 40 percent) immunostained area. Patients with squamous cancer in the high score group recurred earlier than those in the low score group (p $=0.002, \log$ rank test) (Fig. 4a). No differences were found

Table 3: Smac/DIABLO immunostained area in squamous cancer samples.

\begin{tabular}{cccc}
\hline Variable & Median Smac score* & $A D$ & $\boldsymbol{P}$ \\
\hline FIGO stage & & - & 0.55 \\
I & - & 23.64 & \\
III & 31.25 & 17.59 & \\
& 33.22 & & \\
Histology of tumors & & 21.62 & 0.36 \\
Squamous cell & 38.20 & 25.41 & \\
Adenocarcinoma & 34.31 & & \\
Grade & & - & 0.46 \\
Well differentiated & - & 22.43 & \\
Moderately differentiated & 35.71 & 21.50 & \\
Poorly differentiated & 39.60 & &
\end{tabular}

* Immunoreactive percentage area of Smac/DIABLO. AD: absolute median deviation. Kruskall-Wallis test was used for Stage and Grade. Mann-Whitney was used for Histology.
Table 4: Smac/DIABLO inmmunostained area in adenocarcinoma samples.

\begin{tabular}{cccc}
\hline Variable & $\begin{array}{c}\text { Median } \\
\text { Smac } \\
\text { score* }\end{array}$ & AD & $P$ \\
FIGO stage & & & \\
I & 54.00 & 27.01 & 0.13 \\
II & 32.72 & 24.01 & \\
III & 20.83 & 19.08 & \\
Grade & & & \\
Well differentiated & 28.33 & 22.63 & 0.56 \\
Moderately differentiated & 39.37 & 219.98 & \\
Poorly differentiated & 37 & 39.97 & \\
\hline
\end{tabular}

*Immunoreactive percentage area of Smac/DIABLO. AD: absolute median deviation. Kruskall-Wallis test was used to test for differences.

for adenocarcinoma samples (Fig. 4b). Interestingly, Smac/DIABLO staining intensity did not correlate with recurrence (Fig. 4c). In addition, both high and low immunostained area groups presented similar survival rates and distant recurrence rates (Fig. 5).

\section{Discussion}

Apoptosis is a regulated, energy-dependent form of cell death with a characteristic morphological appearance that includes cellular shrinkage and chromatin condensation. It is central to the carcinogenesis process, allowing tumors to proliferate beyond the constraints that limit normal tissue growth. The importance of alterations in apoptosis during carcinogenesis has been confirmed by the finding that deregulated proliferation alone is not sufficient for tumor formation because there is concomitant induction of cell death [21]. It has been shown that tumors commonly present a marked deficiency in mitochondriamediated apoptotic pathways. The most studied case is exemplified by the overexpression of anti-apoptotic members of the bcl-2 family in several malignancies [22]. A less explored area concerns the mechanisms that regulate the apoptotic threshold downstream of the mitochondria. In this regard, it has been shown that IAP overexpression is a poor prognostic marker for a variety of solid tumors and hematological malignancies [23]. In addition, IAPs such as survivin are being investigated as diagnostic markers for the presence of occult malignancy [24]. In cervical cancer, we have recently shown that XIAP and survivin are overexpressed and that XIAP levels correlate with relapse of this disease [25].

Smac/DIABLO is a recently-identified proapoptotic protein that interacts with and inhibits several IAPs, including survivin $[6,9]$. Smac binds to the domain of XIAP that is 


\section{Squamous carcinoma}
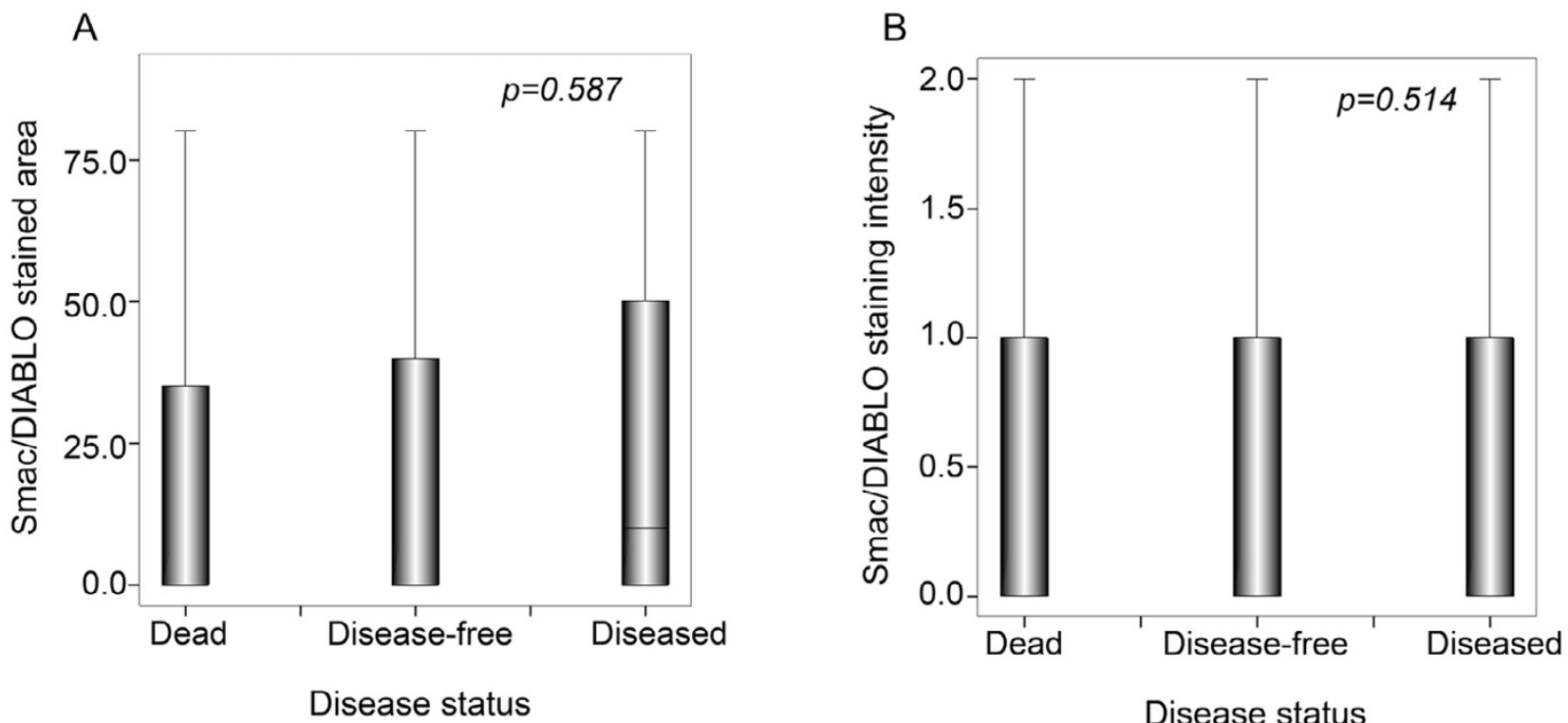

Adenocarcinoma

Disease status

C

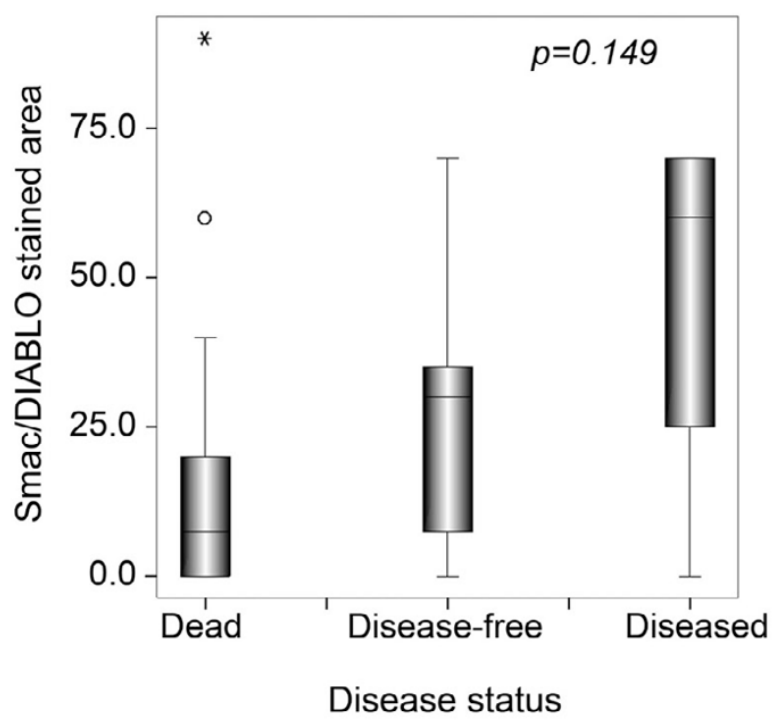

D

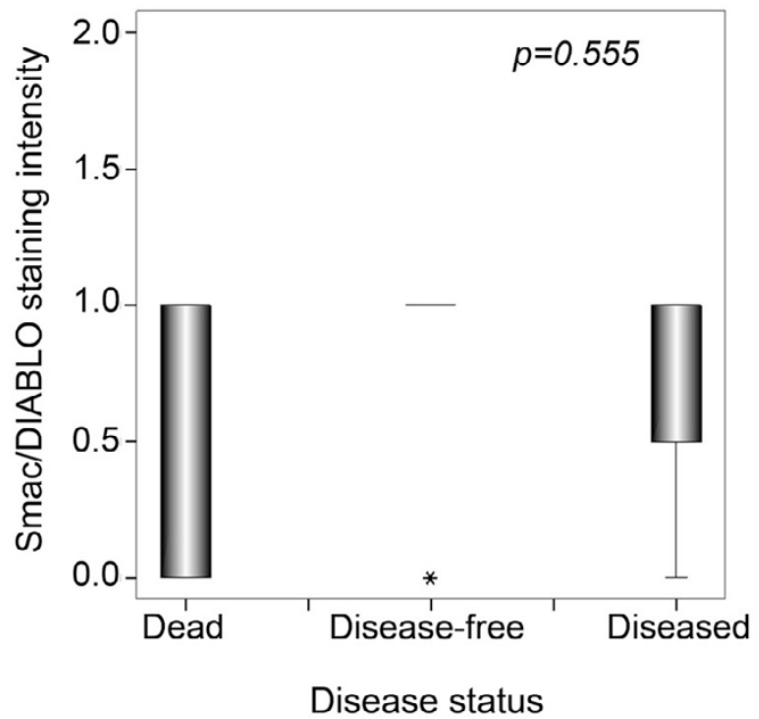

\section{Figure 2}

Smac/DIABLO immunostaining does not correlate with disease status. (A) and (C): Smac/DIABLO immunostained area. (B) and (D): Smac/DIABLO intensity of immunostaining. Scores were calculated as described in Material and Methods. Graphs show median, upper and lower quartiles. P value testing the significance of the difference was determined by Chi square test.

responsible for binding to processed caspase-9, and thus antagonizes the anti-apoptotic function of XIAP. There is also evidence suggesting that the pro-apoptotic function of Smac/DIABLO could be linked to an additional mechanism, different from IAP binding [26]. The role of this protein during carcinogenesis has not been widely explored. It has been shown that Smac/DIABLO mRNA levels are significantly lower in lung cancers than in normal tissues [16]. Patients with lower Smac/DIABLO mRNA levels have worse prognoses. On the other hand, 


\section{Squamous carcinoma}

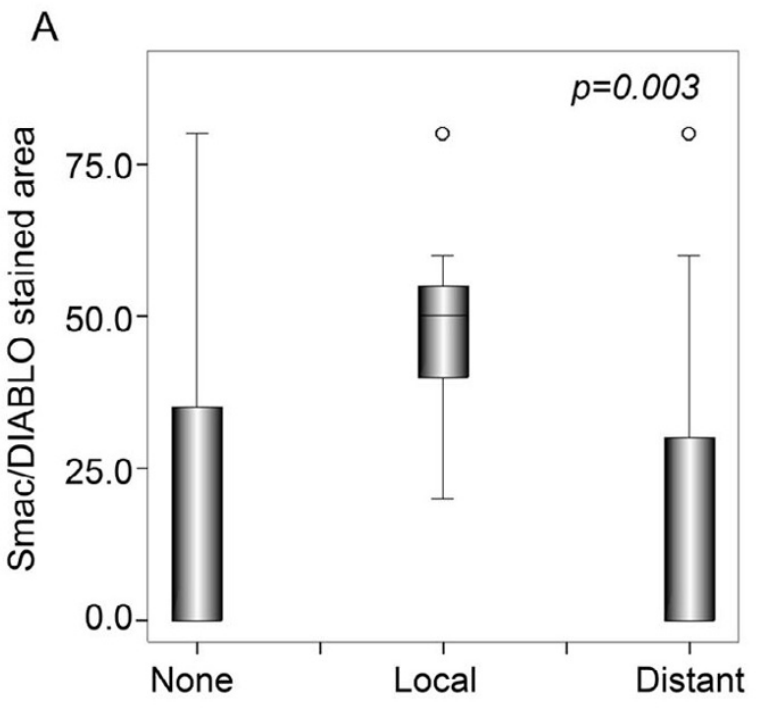

Recurrence

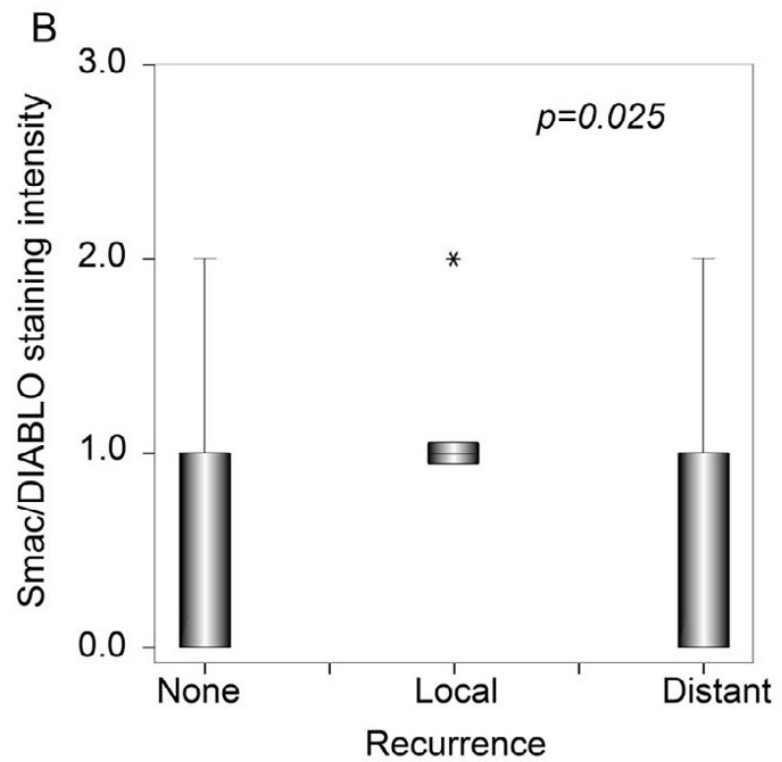

\section{Adenocarcinoma}

C

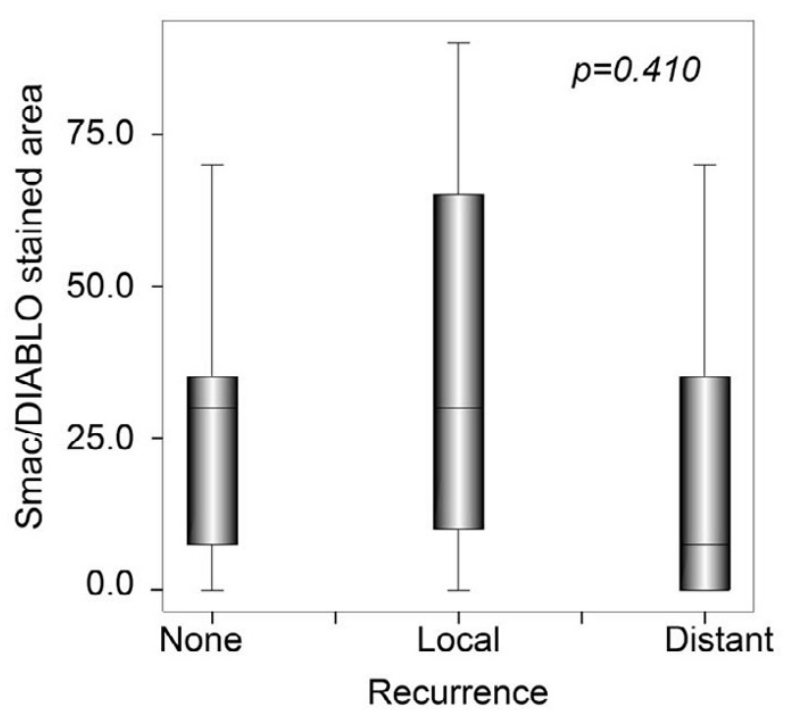

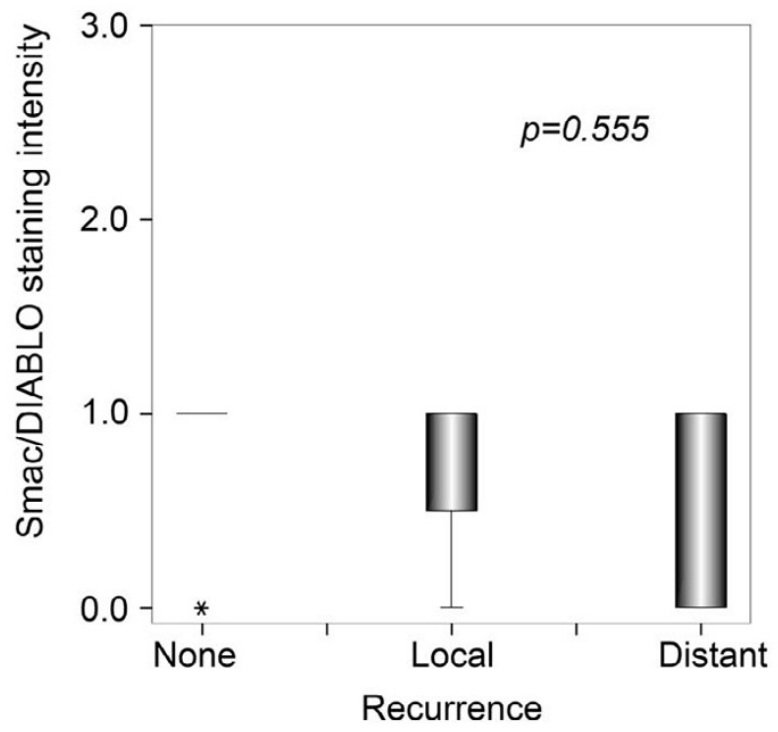

Figure 3

Smac/DIABLO immunostaining correlates with local recurrence in squamous carcinoma. (A) and (C): Smac/DIABLO immunostained area. (B) and (D): Smac/DIABLO intensity of immunostaining. Scores were calculated as described in Material and Methods. Graphs show median, upper and lower quartiles. $P$ value testing the significance of the difference was determined by Chi square test. 
A

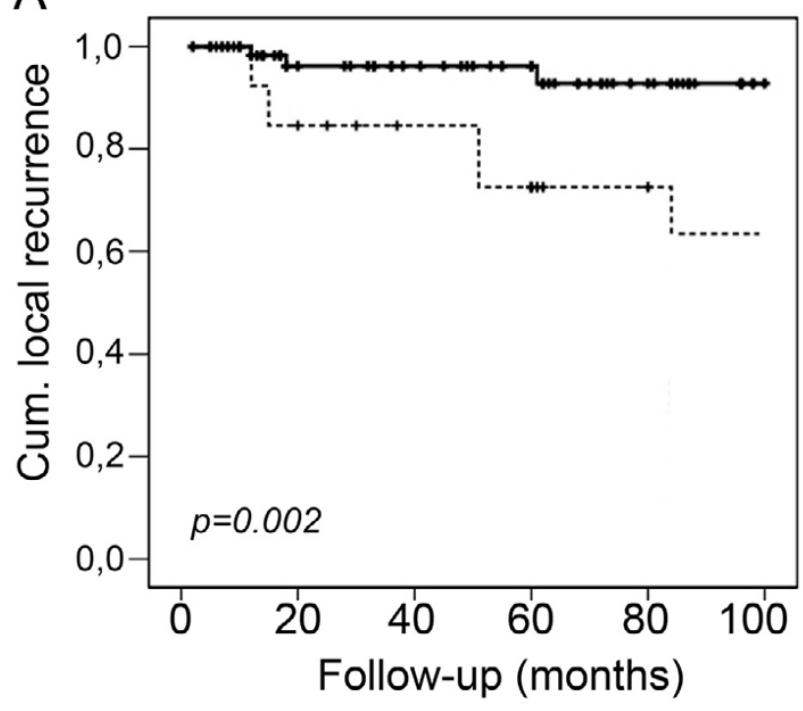

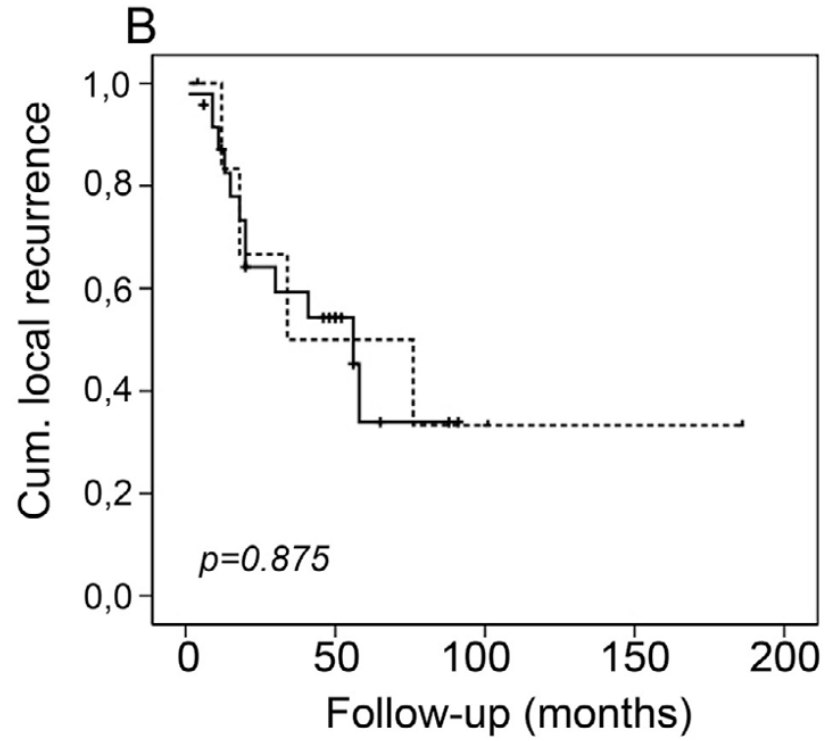

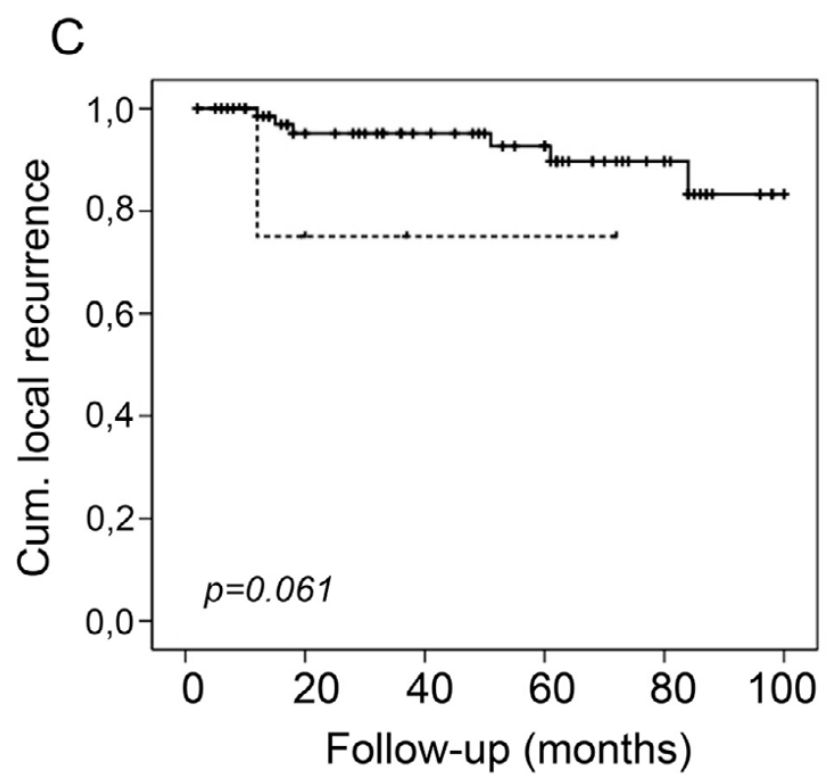

Figure 4

Kaplan-Meier local recurrence estimates in cervical cancer patients by Smac/DIABLO immunostaining. Squamous cell carcinoma samples (A) or adenocarcinoma samples (B), were divided into two groups - low (less than 40 percent) or high (more than 40 percent) immunostained area - and plotted for local recurrence over the time shown (months). Dashed line represents cases with high Smac/DIABLO expression. A similar approach was used for the analysis of intensity of staining in squamous cell carcinoma samples (C). Dashed line represents cases with high intensity. Statistical analysis was performed by log rank test.

we recently reported that during cancer progression, a subset of cervical tumors express this protein de novo [18]. No clinical correlations were found in that study, perhaps reflecting a specific postraductional modulation of Smac/ DIABLO protein. Recent reports have shown that the stability of Smac/DIABLO protein is regulated by its association with several IAPs, including XIAP $[27,28]$, IAP1 and
IAP2 [11]. Survivin also binds to Smac/DIABLO, but it is unable to promote ubiquitination. Since both XIAP and survivin are overexpressed in cervical cancer [25], the level of Smac/DIABLO expression should depend not only on mRNA expression, but also on the balance between these proteins and the release from mitochondria. In the present report, we have shown for the first time that Smac/ 


\section{Squamous carcinoma}
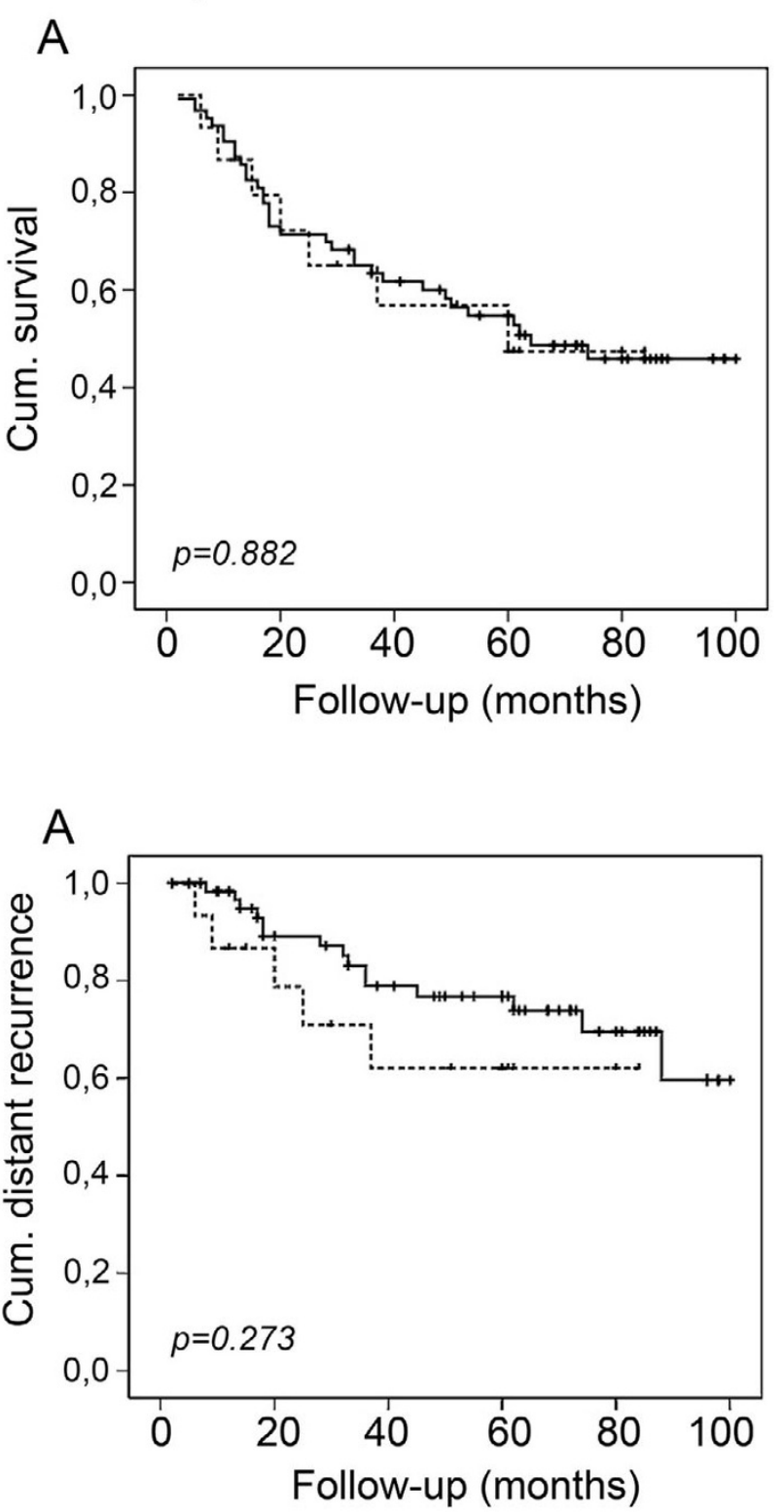

\section{Adenocarcinoma}
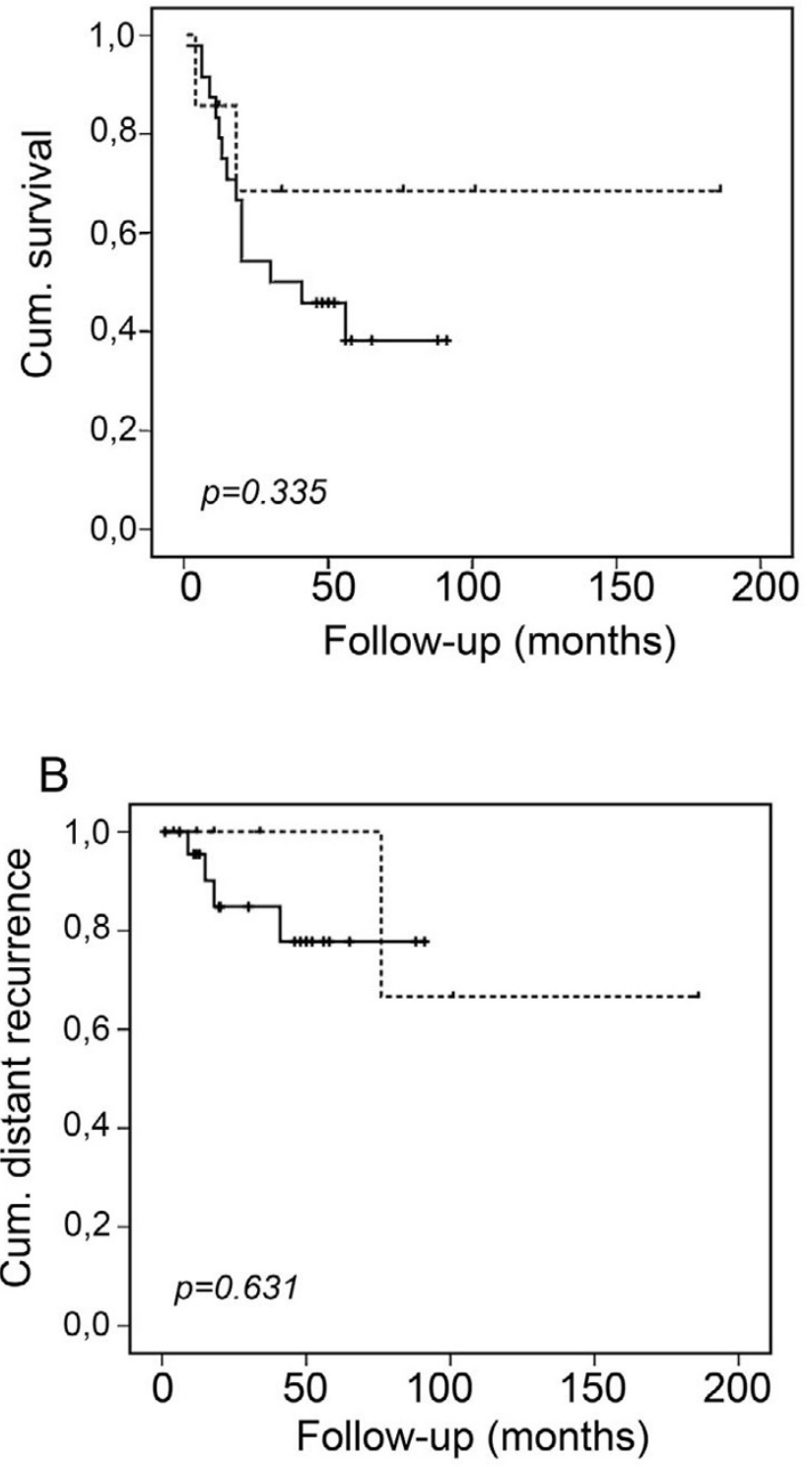

\section{Figure 5}

Kaplan-Meier survival estimates in cervical cancer patients by Smac/DIABLO immunoreactive scores. Patients were divided into two groups - low (less than 40) or high (more than 40) scores - and plotted for survival (A and B) or distant recurrence $(C$ and $D)$ over the time shown (months). Dashed line represents cases with high Smac/DIABLO expression. Statistical analysis was performed by log rank test.

DIABLO protein expression correlates with local recurrence in cervical cancer patients.

The biological reason for this correlation is currently elusive, but several mechanisms could be envisioned. Over- expression of Smac/DIABLO could be related to cancer progression as a response to the enhanced levels of XIAP and survivin, probably selected positively owing to their antiapoptotic activities. This is highly unlikely, since low XIAP mRNA is a marker for earlier recurrence in cervical 
cancer patients [25]. This decrease could have a similar effect to larger amounts of Smac/DIABLO, as in the present report, so it patients with low XIAP would also be expected to have higher Smac/DIABLO expression. Analyses of both proteins in the same panel of patients should help to clarify this. An alternative explanation for the increased incidence of local recurrence in squamous cell carcinoma patients with high Smac/DIABLO immunoreactivity could be related to the recent finding that Smac binds to NADE, a component of the TRAIL death receptor protein complex [29]. In TRAIL-resistant cancer cells, activation of the receptor for this factor leads to a NF-kappa B-mediated increase in tumor invasion and metastasis instead of cell death [30]. Since direct interaction of Smac/ DIABLO with NADE potentiates the signal from the TRAIL receptor, higher Smac expression could lead to an increased invasive potential in resistant cells. Further analysis of the prevalence of TRAIL resistance in cervical tumors should help to clarify this.

An additional contradictory result was the finding of the association of Smac/DIABLO expression with the rate of local recurrence, but not with survival or distant recurrence. Since apoptosis suppression is an important requirement for metastasis, Smac expression could be rendering cervical cancer cells more susceptible to cell death in circulation or, alternatively, to foreign micro ambient compartments, thus counterbalancing the effect of increased local recurrence in prognosis. Supporting this idea, a recent report has shown that XIAP, the main Smac/ DIABLO target, is a negative regulator of anoikis of circulating prostate cancer cells [31]. Additional analyses using transgenic cell lines in animal models should help to validate this hypothesis.

Another interesting observation was that the correlation of Smac/DIABLO with local recurrence was restricted to squamous cell carcinoma patients. It has been previously shown that both histological types represent different pathological entities, since adenocarcinoma tumors have poorer prognoses, metastasize more easily to lymph nodes and are more resistant to radiotherapy than squamous cell tumors [32-34]. From these observations, we can expect important biological differences that could potentially explain our data.

One final interesting finding was the association between Smac/DIABLO levels and microvascular density (MVD). Previous reports have shown that MVD is poor prognosis factor in cervical cancer patients [20]. Patients with MVD higher than 20 presented a higher risk of recurrence. Since Smac/DIABLO immunoreactivity was associated with higher MVD, the early recurrence seen in our patients could be due to enhanced angiogenesis. No published reports have explored the effect of Smac/DIABLO overex- pression on the synthesis of pro-angiogenic molecules, or vice versa, although the association of Smac with signal transduction complexes [29,35] and the activation of the NF-kappa B pathway could provide a possible mechanism for the synthesis of angiogenic molecules.

\section{Conclusion}

The present report shows that high Smac/DIABLO immunoreactivity is associated with a higher rate of recurrence in cervical squamous cell carcinoma patients. In addition, Smac/DIABLO expression correlated positively with microvascular density in these patients. Further studies directed at elucidating the role of Smac/DIABLO in the recurrence and invasion of cervical cancer are clearly needed.

\section{Competing interests}

The author(s) declare that they have no competing interests.

\section{Authors' contributions}

AAL: Collected the patient data and performed the photomicrography and immunohistochemistry.

FJG: Collaborated in the immunohistochemistry.

DP: Performed the pathology analyses and MVD assays.

DC: Collaborated in clinical assessment of the patients and results.

ME: Collaborated in the pathology analyses

JGD: Collaborated in data analyses and clinical assessment.

VM: Performed the statistical analyses. She also collaborated in editing the manuscript.

JMZ: Designed the study. Coordinated the group. Edited the manuscript.

All authors read and approved the final manuscript

\section{Acknowledgements}

This work was supported by grants CONACYT-SEP 2004-C0 I-45728/

A-I and SALUD-2002-C0I-6579 from Consejo Nacional de Ciencia y Tecnolología, México.

\section{References}

I. Uren AG, Coulson EJ, Vaux DL: Conservation of baculovirus inhibitor of apoptosis repeat proteins (BIRPs) in viruses, nematodes, vertebrates and yeasts. Trends Biochem Sci 1998, 23(5): 159-162.

2. Shi $Y$ : Mechanisms of caspase activation and inhibition during apoptosis. Mol Cell 2002, 9(3):459-470.

3. Wang $X$ : The expanding role of mitochondria in apoptosis. Genes Dev 200I, I 5(22):2922-2933. 
4. Deveraux QL, Reed JC: IAP family proteins--suppressors of apoptosis. Genes Dev 1999, 13(3):239-252.

5. Shi $Y$ : A conserved tetrapeptide motif: potentiating apoptosis through IAP-binding. Cell Death Differ 2002, 9(2):93-95.

6. Du C, Fang M, Li Y, Li L, Wang X: Smac, a mitochondrial protein that promotes cytochrome c-dependent caspase activation by eliminating IAP inhibition. Cell 2000, 102(I):33-42.

7. Verhagen AM, Ekert PG, Pakusch M, Silke J, Connolly LM, Reid GE, Moritz RL, Simpson RJ, Vaux DL: Identification of DIABLO, a mammalian protein that promotes apoptosis by binding to and antagonizing IAP proteins. Cell 2000, I02(I):43-53.

8. Srinivasula SM, Datta P, Fan XJ. Fernandes-Alnemri T, Huang Z, Alnemri ES: Molecular determinants of the caspase-promoting activity of Smac/DIABLO and its role in the death receptor pathway. J Biol Chem 2000, 275(46):36I52-36I57.

9. Song Z, Yao X, Wu M: Direct interaction between survivin and Smac/DIABLO is essential for the anti-apoptotic activity of survivin during taxol-induced apoptosis. I Biol Chem 2003, 278(25):23|30-23140.

10. Vucic D, Deshayes K, Ackerly H, Pisabarro MT, Kadkhodayan S, Fairbrother WJ, Dixit VM: SMAC negatively regulates the antiapoptotic activity of melanoma inhibitor of apoptosis (MLIAP). J Biol Chem 2002, 277( (14): I 2275- 22279.

II. Yang QH, Du C: Smac/DIABLO selectively reduces the levels of c-IAPI and c-IAP2 but not that of XIAP and livin in HeLa cells. J Biol Chem 2004, 279(17): 16963-16970.

12. Yang L, Cao Z, Yan H, Wood WC: Coexistence of high levels of apoptotic signaling and inhibitor of apoptosis proteins in human tumor cells: implication for cancer specific therapy. Cancer Res 2003, 63(20):6815-6824.

13. Tanaka K, Iwamoto S, Gon G, Nohara T, Iwamoto M, Tanigawa N: Expression of survivin and its relationship to loss of apoptosis in breast carcinomas. Clin Cancer Res 2000, 6(1): 127-134.

14. Ferreira CG, van der Valk P, Span SW, Jonker JM, Postmus PE, Kruyt FA, Giaccone G: Assessment of IAP (inhibitor of apoptosis) proteins as predictors of response to chemotherapy in advanced non-small-cell lung cancer patients. Ann Oncol 200I, I 2(6):799-805.

15. Hong X, Lei L, Glas R: Tumors acquire inhibitor of apoptosis protein (IAP)-mediated apoptosis resistance through altered specificity of cytosolic proteolysis. J Exp Med 2003, 197(1 2): I73|-1743.

16. Sekimura A, Konishi A, Mizuno K, Kobayashi Y, Sasaki H, Yano M, Fukai I, Fujii Y: Expression of Smac/DIABLO is a novel prognostic marker in lung cancer. Oncol Rep 2004, II (4):797-802.

17. Mizutani Y, Nakanishi H, Yamamoto K, Li YN, Matsubara H, Mikami K, Okihara K, Kawauchi A, Bonavida B, Miki T: Downregulation of Smac/DIABLO expression in renal cell carcinoma and its prognostic significance. J Clin Oncol 2005, 23(3):448-454.

18. Espinosa M, Cantu D, Lopez CM, De la Garza JG, Maldonado V, Melendez-Zajgla J: SMAC is expressed de novo in a subset of cervical cancer tumors. BMC Cancer 2004, 4(I):84.

19. Yoo NJ, Kim HS, Kim SY, Park WS, Park CH, Jeon HM, Jung ES, Lee JY, Lee SH: Immunohistochemical analysis of Smac/DIABLO expression in human carcinomas and sarcomas. Apmis 2003, I I I(3):382-388.

20. Cantu De Leon D, Lopez-Graniel C, Frias Mendivil M, Chanona Vilchis G, Gomez C, De La Garza Salazar J: Significance of microvascular density (MVD) in cervical cancer recurrence. Int J Gynecol Cancer 2003, I 3(6):856-862.

21. Evan GI, Vousden $\mathrm{KH}$ : Proliferation, cell cycle and apoptosis in cancer. Nature 200I, 4 I I (6835):342-348.

22. Strasser A, Huang DC, Vaux DL: The role of the bcl-2/ced-9 gene family in cancer and general implications of defects in cell death control for tumourigenesis and resistance to chemotherapy. Biochim Biophys Acta 1997, I333(2):FI5I-78.

23. Nachmias $B$, Ashhab $Y$, Ben-Yehuda $D$ : The inhibitor of apoptosis protein family (IAPs): an emerging therapeutic target in cancer. Semin Cancer Biol 2004, I4(4):231-243.

24. Schimmer AD: Inhibitor of apoptosis proteins: translating basic knowledge into clinical practice. Cancer Res 2004, 64(20):7183-7190.

25. Espinosa M, Cantu D, Herrera N, Lopez CM, De la Garza JG, Maldonado $\mathrm{V}$, Melendez-Zajgla J: Inhibitors of apoptosis proteins in human cervical cancer. BMC Cancer 2006, 6:45.
26. Roberts DL, Merrison W, MacFarlane M, Cohen GM: The inhibitor of apoptosis protein-binding domain of Smac is not essential for its proapoptotic activity. J Cell Biol 200I, I 53(I):22I-228.

27. MacFarlane M, Merrison W, Bratton SB, Cohen GM: Proteasomemediated degradation of Smac during apoptosis: XIAP promotes Smac ubiquitination in vitro. J Biol Chem 2002, 277(39):366||-366|6.

28. Morizane $\mathrm{Y}$, Honda R, Fukami K, Yasuda $\mathrm{H}$ : X-linked inhibitor of apoptosis functions as ubiquitin ligase toward mature caspase-9 and cytosolic Smac/DIABLO. J Biochem (Tokyo) 2005, 137(2): $125-132$.

29. Yoon K, Jang HD, Lee SY: Direct interaction of Smac with NADE promotes TRAIL-induced apoptosis. Biochem Biophys Res Commun 2004, 3 I 9(2):649-654.

30. Malhi $\mathrm{H}$, Gores $\mathrm{GJ}$ : TRAIL resistance results in cancer progression: a TRAIL to perdition? Oncogene 2006.

31. Berezovskaya O, Schimmer AD, Glinskii AB, Pinilla C, Hoffman RM, Reed JC, Glinsky GV: Increased expression of apoptosis inhibitor protein XIAP contributes to anoikis resistance of circulating human prostate cancer metastasis precursor cells. Cancer Res 2005, 65(6):2378-2386.

32. Kosary CL: FIGO stage, histology, histologic grade, age and race as prognostic factors in determining survival for cancers of the female gynecological system: an analysis of 1973-87 SEER cases of cancers of the endometrium, cervix, ovary, vulva, and vagina. Semin Surg Oncol 1994, I O(I):3 I-46.

33. Lea JS, Sheets EE, Wenham RM, Duska LR, Coleman RL, Miller DS, Schorge JO: Stage IIB-IVB cervical adenocarcinoma: prognostic factors and survival. Gynecol Oncol 2002, 84(I): II5-II9.

34. Quinn MA: Adenocarcinoma of the cervix--are there arguments for a different treatment policy? Curr Opin Obstet Gynecol 1997, 9(I):21-24.

35. Kuai J, Nickbarg E, Wooters J, Qiu Y, Wang J, Lin LL: Endogenous association of TRAF2, TRAF3, clAPI, and Smac with lymphotoxin beta receptor reveals a novel mechanism of apoptosis. J Biol Chem 2003, 278( (16): I 4363-I4369.

\section{Pre-publication history}

The pre-publication history for this paper can be accessed here:

http://www.biomedcentral.com/1471-2407/6/256/pre pub

Publish with Bio Med Central and every scientist can read your work free of charge

"BioMed Central will be the most significant development for disseminating the results of biomedical research in our lifetime. "

Sir Paul Nurse, Cancer Research UK

Your research papers will be:

- available free of charge to the entire biomedical community

- peer reviewed and published immediately upon acceptance

- cited in PubMed and archived on PubMed Central

- yours - you keep the copyright
BioMedcentral 